\title{
Consulta popular e os planejamentos regionais no Rio Grande do Sul: intersecções e resultados
}

\section{Popular consultation and regional planning in Rio Grande do Sul: intersections and results}

Victor da Silva Oliveira - Universidade Federal de Pernambuco. Mestre em Desenvolvimento Regional, Universidade de Santa Cruz do Sul, 2013, doutorando em Geografia pela Universidade Federal de Pernambuco/ UFPE. victorsoliveira@hotmail.com

Erica Karnopp - Universidade de Santa Cruz do Sul. Doutora em Geografia pela Universität Tübingen Alemanha, 2004). Docente do Departamento de História e Geografia e do Programa de Pós-Graduação em Desenvolvimento Regional - Mestrado e Doutorado da Universidade de Santa Cruz do Sul/UNISC e pósdoutoranda em Geografia pela Universität Innsbruck - Áustria. erica@unisc.br

\section{Resumo}

O desenvolvimento na perspectiva territorial necessita uma intervenção de modo coerente e organizada. Os planejamentos em diferentes escalas e segmentos apresentam-se como um meio para esta intervenção ocorrer satisfatoriamente e, se realizados de forma participativa, com a presença da sociedade civil e seus representantes. Não obstante, os orçamentos participativos oferecem uma forma da população se fazer ouvir democraticamente e ter atendidas suas carências. Desta forma, o presente artigo, que possui o Estado do Rio Grande do Sul como objeto de pesquisa, pretendeu analisar as demandas eleitas pela Consulta Popular em 2010 a fim de considerar se foram contempladas através dos planos estratégicos dos Conselhos Regionais de Desenvolvimento - COREDEs (2009/2010). Tendo em vista fundamentar a análise foi realizada uma pesquisa bibliográfica, além de uma pesquisa documental dos planos regionais de desenvolvimento. Os resultados apresentaram uma díspar relação entre os COREDEs. No entanto uma constatação foi comum a todos. A preocupação com as necessidades básicas foram amplamente eleitas na consulta popular e proposta nos planejamentos regionais. Não há como negar a importância da segurança pública, por exemplo, entretanto, antes de tudo essa é uma necessidade básica, não atende rigorosamente a um projeto de desenvolvimento, sendo que os mecanismos analisados estão sendo utilizados de forma equivocada, não para criar projetos de intervenção visando o desenvolvimento, mas sim para sanar carências em que o Estado não está suficientemente atendendo a população.

\section{Palavras-chave}

planejamento regional, orçamento participativo, consulta popular.

\begin{abstract}
The development on the territorial perspective needs an intervention in a coherent and organized way. The planning at different scales and segments are presented as means to this intervention occur satisfactorily and, if conducted in a participatory way, with the presence of civil society and its representatives. Nevertheless, participatory budgets offer a way of making people listen democratically and have their needs met. Thus, this article, which has the state of Rio Grande do Sul as the research object, intended to analyze the demands elected by Popular Consultation in 2010 to consider whether they were covered by the strategic plans of the Regional Development Councils - COREDEs (2009/2010). In order to give corroborate the analysis, was performed a literature research, and a documentary research in regional development plans. The results showed a scatter relationship between COREDEs. However a finding was common to all. The concern with basic needs were largely elected on popular consultation and were proposed in the regional plans. There is no denying the importance of public safety, for example, however, first and foremost this is a basic need, not strictly attends to a development project, and analyzed the mechanisms are being used wrongly, not to create projects intervention for the development, but to remedy deficiencies where the state is not adequately serving the population.
\end{abstract}

\section{Keywords}

regional planning, participatory budgeting, popular consultation. 


\section{INTRODUÇÃO}

Com o redirecionamento da concepção de desenvolvimento, superando a perspectiva verticalizada ${ }^{1}$, por uma horizontal, que concebe a formação territorial, pensar o planejamento regional apresenta-se como aspecto fundamental, visto que a parir deste almeja-se uma transformação em nível socioeconômico. Porém não basta planejar, deve-se aplicar o proposto contido nos documentos. Este é um grande desafio dos gestores, ou seja, fazer valer o planejamento. No Estado do Rio Grande do Sul, a Consulta Popular, forma de orçamento participativo, é um importante mecanismo para materializar as proposições dos planos.

O governo do Estado do Rio Grande do Sul, por intermédio do Fórum dos COREDEs, desenvolveu no biênio 2009/2010 os planos estratégicos de desenvolvimento de vinte e sete COREDEs, os quais foram realizados, considerando a metodologia adotada, de maneira participativa e construídos por agentes públicos regionais. Já durante a realização dos planos, um desafio que se colocou foi como realizar os projetos por estes mencionados. Desta preocupação, o Fórum dos COREDEs definiu que, entre as demandas elencadas para votação na Consulta Popular, deveriam estar as conclusões dos planejamentos.

Desta forma, o presente trabalho tem o objetivo de responder a seguinte questão: os planejamentos regionais, realizados pelos COREDEs nos anos de 2009/2010, foram considerados nas demandas eleitas da consulta popular de 2010 ?

Para responder tal questionamento foi realizada uma pesquisa bibliográfica para fundamentar a temática proposta além de uma pesquisa documental dos planos regionais. A partir destas técnicas buscou-se contemplar o seguinte objetivo: analisar as demandas eleitas pela consulta popular em 2010 a fim de considerar se foram contemplados os projetos propostos pelos planos estratégicos dos COREDEs (2009/2010).

\section{REGIÃO, PLANEJAMENTO E ORÇAMENTO PARTICIPATIVO: ESCALA E PROCEDIMENTOS PARA O DESENVOLVIMENTO}

A acumulação fordista, difundida a partir do método fabril criado por Henry Ford nos Estados Unidos e aplicado primeiramente nas linhas

Conceitos analisados por Santos (1996) ao referir-se as transformações nas redes que garantem a interdependência de diferentes espaços e reflete a imposição de decisões externas aos locais/ regiões onde as repercussões se materializam.

Novos Cadernos NAEA • v. 17 n. $1 \cdot$ p. 161-176 • jun. 2014 
de produção automobilísticas, segundo Harvey (1992), difundiram uma territorialização baseada em si própria, em que o desenvolvimento era a sinônimo de industrialização/urbanização, introduzindo na sociedade necessidades antes ausente, modificando-a socioeconomicamente.

Concomitante a difusão desta concepção de desenvolvimento, nas ideias do mesmo autor acima mencionado, alastrava-se também o discurso homogeneizador - em distintos aspectos - que o período iria causar, justamente por se territorializar em diferentes espaços e desconsiderar aspectos particulares, sendo que, independentemente de qual cultura, história e patrimônio natural existente nas regiões, esta forma de produção e reprodução de capital instalou-se visando uma única meta: maximizar os lucros.

Contudo, apesar do discurso homogeneizador do capitalismo, pode-se afirmar que apenas como meio de produção atinge alguma padronização, pois socio-territorialmente não, ao contrário, aprofunda as distinções espaciais. A implantação de indústrias de forma vertical, como conceitua Santos (1996), sem considerar a base territorial em que está alicerçada, privilegiando determinados lugares que para o grande capital expõe melhores condições para receber tais empreendimentos, apenas atenua as diferenças, pois estes acabam por serem privilegiados - não ocasionalmente - com maior incidência de fixos a fim de garantir a reprodução de tal(is) empresa(s) capitalista(s).

Em contrapartida ${ }^{2}$, emerge a necessidade de uma nova concepção de desenvolvimento, não mais isenta de identidade territorial e competitividade baseada apenas em custos de produção. Fazendo uso das ideias de Benko (1999) sobre o desenvolvimento regional, a insuficiência do modelo fordista clássico traz à tona a necessidade de uma visão territorial relacionada ao desenvolvimento que tenha como ponto de partida ações com recursos locais com a interação social.

Neste sentido, Pecqueur (2009) cita a qualificação do produto em uma economia norteada pela diferenciação do mesmo, agregando valor de forma que a concorrência não ocorra exclusivamente por preços ou custos de produção vantagem comparativa Ricardiana -, mas pela sua customização, surgindo assim, como denomina o autor, uma 'economia geográfica'.

A partir desta breve reflexão sobre o redirecionamento realizado no século XX na perspectiva de desenvolvimento, passando de um desenvolvimento sem vínculo territorial para uma economia baseada nas próprias particularidades territoriais, nota-se a retomada da discussão sobre o conceito região e a ciência regional. Além disso, questiona-se também como pensar e promover um

2 Justamente pela crise do sistema de produção fordista como afirma Benko (1999). 
desenvolvimento de cunho territorial. Neste sentido, planejar e considerar a opinião dos agentes que posteriormente atuarão na transformação da realidade se faz necessário.

Diversas são as concepções sobre região, visto que é uma escala de análise e ação utilizadas por diversas ciências, como Sociologia, Geografia, História, Economia, entre outras. Contudo certos pontos de intersecção existem, como a diferença territorial, no sentido de que a região é tida como unidades de área que apresentam determinada semelhança interna, sejam elas naturais, culturais, físicas, etc. São estas particularidades que a região carrega onde autores como Pecqueur (2009), Flores (2006), Benko (1999) e Santos (2000) concebem sendo as matrizes para o desenvolvimento com bases territoriais.

Para auferir o desenvolvimento concebido pelos autores acima mencionados, intervir em uma região de modo a esmo seria como um equívoco visto a complexidade hoje vinculada à região. Lencioni (2001) ressalta essa questão afirmando que esta complexidade ocorre devido à dialética das relações global/regional existente atualmente, ou seja, a análise regional não pode ser realizada sem estabelecer uma correlação com os processos globais, pois caso não haja este cuidado, teremos uma visão fragmentada e desconecta rompendo com a realidade.

Portanto, o planejamento apresenta-se como uma forma possível para abranger esta gama de fluxos que intervém no espaço regional, assim como delineia as ações a serem realizadas no futuro visando o desenvolvimento. $\mathrm{O}$ planejamento, para Holanda (1983), tem o objetivo justamente de apontar caminhos para a elevação dos níveis de renda e de bem-estar de uma determinada comunidade, reordenando a conjuntura posta e sistematizando as decisões dos objetivos a serem alcançados.

Considerando este objetivo que o planejamento busca auferir, ter clareza conceitual sobre a temática é imprescindível. Siedenberg (2010, p. 29) abordando o planejamento numa perspectiva territorial, alega ser complexa a definição do termo, porém afirma que este "diz respeito ao levantamento de informações fundamentais para deliberar sobre opções consistentes, visando propor ações oportunas ao desenvolvimento de um determinado espaço".

Acrescentando a conceituação a questão regional, Boisier (2000) ${ }^{3}$ aborda o planejamento regional a partir do seu uso para descrever o conjunto de propostas traçadas para estimular processos de crescimento, e eventualmente, de desenvolvimento.

3 Disponível em http://www.perm.org.ar/biblioteca/articulos/ del_\%20desarrollo_territorial....pdf

Novos Cadernos NAEA • v. 17 n. 1 • p. 161-176 • jun. 2014 
Em ambos os conceitos mencionados nota-se a perspectiva de mudança que se almeja ao se planejar uma região. Considerando a reflexão realizada anteriormente, pode-se nortear um planejamento visando evidenciar as particularidades da região e promover a partir destas, e com ações que a fomentem como geradoras e agregadoras de renda, uma transformação.

Entretanto deve-se considerar a que forma este planejamento é realizado, pois, sem considerar a participação dos agentes diretos que serão beneficiados com os resultados posteriores a implementação do planejamento, parcas são as perspectivas positivas, já que possivelmente não haverá adesão de tais agentes. Corroborando com estas ideias, Dallabrida (2004, p. 42) afirma que:

O planejamento não é tarefa somente dos 'planejadores', como os técnicos que tudo sabem. Isto, pois, o planejamento tanto pode ser utilizado para emancipar, como para dominar. Normalmente, é nos escritórios distantes da realidade que de decidem os caminhos a serem trilhados pelas comunidades. Nada mais equivocado! Sem uma participação efetiva dos atingidos, nenhum plano tem sucesso. Trata-se de colocar o conhecimento técnico de planejadores a serviço da emancipação das pessoas e das comunidades. Nessa concepção, o que fazer sempre será definido pelos agentes diretos, pelos interessados imediatos nos resultados do planejamento.

Nessa perspectiva, visando intervir nas regiões do Rio Grande do Sul de forma estruturada e com a participação social no processo de planejamento, o governo do Estado (gestão Yeda Crusius - 2007/2010) contatou o Fórum dos COREDEs para a construção de planejamentos regionais das vinte e oito ${ }^{4}$ regiões coredianas.

A realização destes planos teve início com a capacitação dos agentes que iriam realizar os planejamentos. Esta etapa foi realizada no município de Santa Maria em maio de 2009 com o apoio teórico-metodológico da Comissão Econômica para América Latina e Caribe (ILPES/CEPAL). Além da capacitação, foi definida a metodologia a ser adotada pelos Conselhos na elaboração dos planos, a qual foi apresentada posteriormente em Siedenberg (2009).

Considerando a metodologia adotada, percebe-se fortemente a conotação participativa que esta propõe, visto que a cada conjunto de duas ou três etapas ${ }^{5}$ realizadas pelos planejadores, é estabelecida a formalização e discussão dos

\footnotetext{
O COREDE Norte, que abrange o município de Erechim, decidiu não realizar o planejamento pois no ano de 2008 foi lançado o planejamento local de Erechim, denominado 'Erechim 2018'. Já o COREDE Delta do Jacuí, o qual inclui a capital do Estado Porto Alegre, não elaborou o plano.

5 As etapas são as seguintes: 1.Diagnóstico técnico; 2.Análise Situacional; 3.Matriz FOFA; 4.Referenciais Estratégicos; 5.Macro-objetivos; 6. Definição de Modelo de Gestão do Processo; e 7. Divulgação / Implementação.
} 
resultados junto a gestores, entidades pertinentes e sociedade civil organizada, que transcrevem comentários e auxiliam na elaboração do documento.

Os planos resultaram em diversas estratégias, programas e projetos tidos como prioritários para o desenvolvimento das regiões. Entretanto, poucas são as perspectivas de implementação destes projetos, vista a incapacidade financeira e estrutural dos Conselhos em até mesmo gerir os planos. Uma propocisão então vinda do Forum dos COREDEs surgiu como uma saída para esta incapacidade dos Conselhos e para a inercia do Estado. O Forum propôs que os planos fossem considerados para elencação das demandas a serem votadas pelos eleitores na Consulta Popular, realizada anualmente.

A Consulta Popular, de acordo com Fórum dos Conselhos Regionais de Desenvolvimento do Rio Grande do Sul (2010), surgiu ${ }^{6}$ na administração estadual de Antônio Britto (1995/1998) determinando que o Poder Executivo promovese, anualmente, uma consulta direta à população para determinar investimentos de interesse regional de uma parcela do orçamento do Estado - que corresponde a menos de $1 \%$ do orçamento.

A Consulta Popular enquadra-se na concepção de orçamento participativo, que consiste na participação da sociedade organizada na tomada de decisões e norteamento de investimentos. Pires (2001, p. 35) relata que o orçamento participativo representa um aperfeiçoamento político e neste "não somente os parlamentares devem participar das decisões sobre finanças e políticas públicas: a população organizada, a sociedade civil assume papel ativo, passa a ser agente e não mero paciente".

Sobre o papel da Consulta Popular como um conceito de orçamento participativo e assim considerando as opiniões da sociedade civil organizada no processo de delineamento das demandas regionais, Bugs (2011, p. 21) acrescenta que:

pode-se considerar a Consulta Popular como um processo de política de inclusão, oportunidade disponibilizada pelo Governo do Estado para que a sociedade civil possa participar ativamente através da definição das necessidades, prioridades e potencialidades e, posteriormente, pela homologação através do voto, na decisão de projetos relevantes para o desenvolvimento da sua região.

Tendo como base estas duas ferramentas reconhecidas e utilizadas pelo governo do Rio Grande do Sul, pretendeu-se analisar se há uma intersecção de ambas ações, ou seja, se os planejamentos regionais estão sendo contemplados nas demandas eleitas pela Consulta Popular, visto que, além de haver uma orientação

$6 \quad$ Através da Lei Estadual n 11.179 de 25 de junho de 1998.

Novos Cadernos NAEA • v. 17 n. $1 \bullet$ p. 161-176 • jun. 2014 
do Forum dos COREDEs para considerar os resultados de tais planos, os mesmo agentes que o confeccionaram - considerando que os Conselhos seguiram a metodologia proposta e realizaram o planejamento de forma participativa votam na escolha das prioridades para o desenvolvimento das regiões.

Nesse contexto de redirecionamento da concepção de desenvolvimento, em que se considera a perspectiva territorial não apenas como meio, mas como aspecto principal para a transformação em todas as facetas da sociedade, analisar planejamentos que visam essa intervenção na realidade e que, consideram a participação de entidades, lideres políticos e a sociedade civil organizada na indicação de projetos visando o desenvolvimento regional, surge como uma importante tangente na concepção dos caminhos que o desenvolvimento territorial no Rio Grande do Sul está trilhando. Somando-se a isso, conferir se tais proposições estão sendo contempladas nas demandas eleitas na Consulta Popular, principal meio até então de materialização dos planos, acrescenta para a discussão se os mecanismos participativos do Estado estão sendo eficientes - e em que medida - ou não.

\section{METODOLOGIA DE ANÁLISE DO PLANEJAMENTO REGIONAL E DAS DEMANDAS ELEITAS PELA CONSULTA POPULAR}

Para a realização desta pesquisa foram utilizadas duas principais técnicas, a revisão bibliográfica e análise documental, como denomina Trivinõs (2001).

A revisão bibliográfica baseou-se na busca por autores que pesquisam e discutem os temas centrais do presente artigo, a região, visto que está se discutindo esta escala de análise; o planejamento, como os realizados pelos COREDEs em 2009/2010, sendo um meio para diagnóstico e proposição de um norteamento para o desenvolvimento regional; e por fim o orçamento participativo - no qual se enquadra a Consulta Popular, objeto de análise - onde a sociedade civil tem força de decisão para os investimentos julgados prioritários.

A pesquisa documental teve por finalidade investigar os projetos elencados pelos planejamentos regionais dos COREDEs em 2009/2010. Para abranger uma representatividade considerável de planos, foi considerada a regionalização das Regiões Funcionais, como apresenta a figura 1, divisão apresentada por Rio Grande do Sul (2006) no estudo 'Rumos 2015’ e divide o Estado em nove Regiões Funcionais respeitando os limites dos vinte e oito COREDEs. 
Figura 1 - Regiões Funcionais do Rio Grande do Sul.

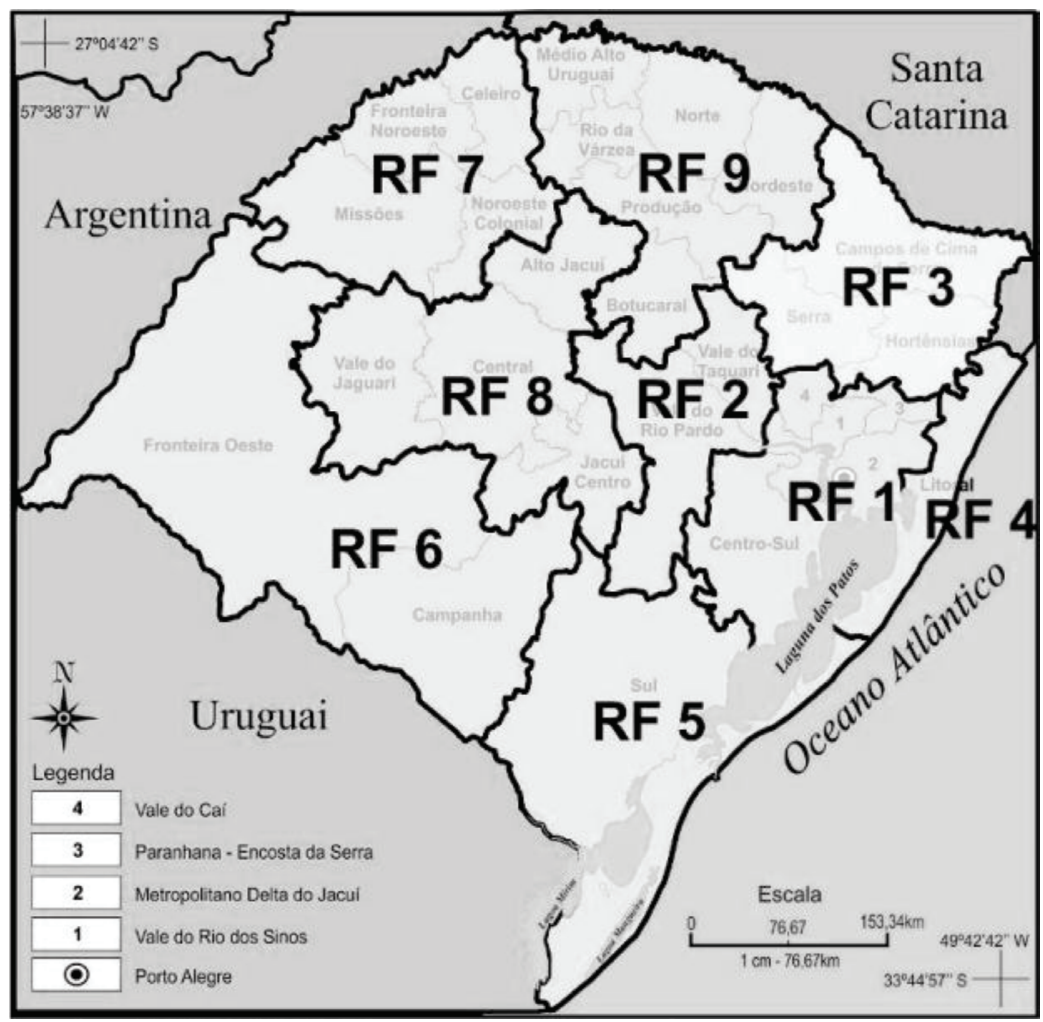

Fonte: Rio Grande do Sul (2006), adaptado pelo autor.

A partir destas considerações, foram analisados nove COREDEs, um de cada Região Funcinal. Os planos dos seguintes Conselhos foram concebidos, como apresenta a figura 2: COREDE Paranhana-Encosta da Serra (Região Funcional 1); COREDE Vale do Rio Pardo (Região Funcional 2); COREDE Hortências (Região Funcional 3); COREDE Litoral Norte (Região Funcional 4); COREDE Sul (Região Funcional 5); COREDE Fronteira Oeste (Região Funcional 6); COREDE Missões (Região Funcional 7); COREDE Central (Região Funcional 8); e COREDE Médio Alto Uruguai (Região Funcional 9). 
Figura 2 - Regiões Funcionais do Rio Grande do Sul e Conselhos Regionais de Desenvolvimento (COREDEs). COREDEs analisados.

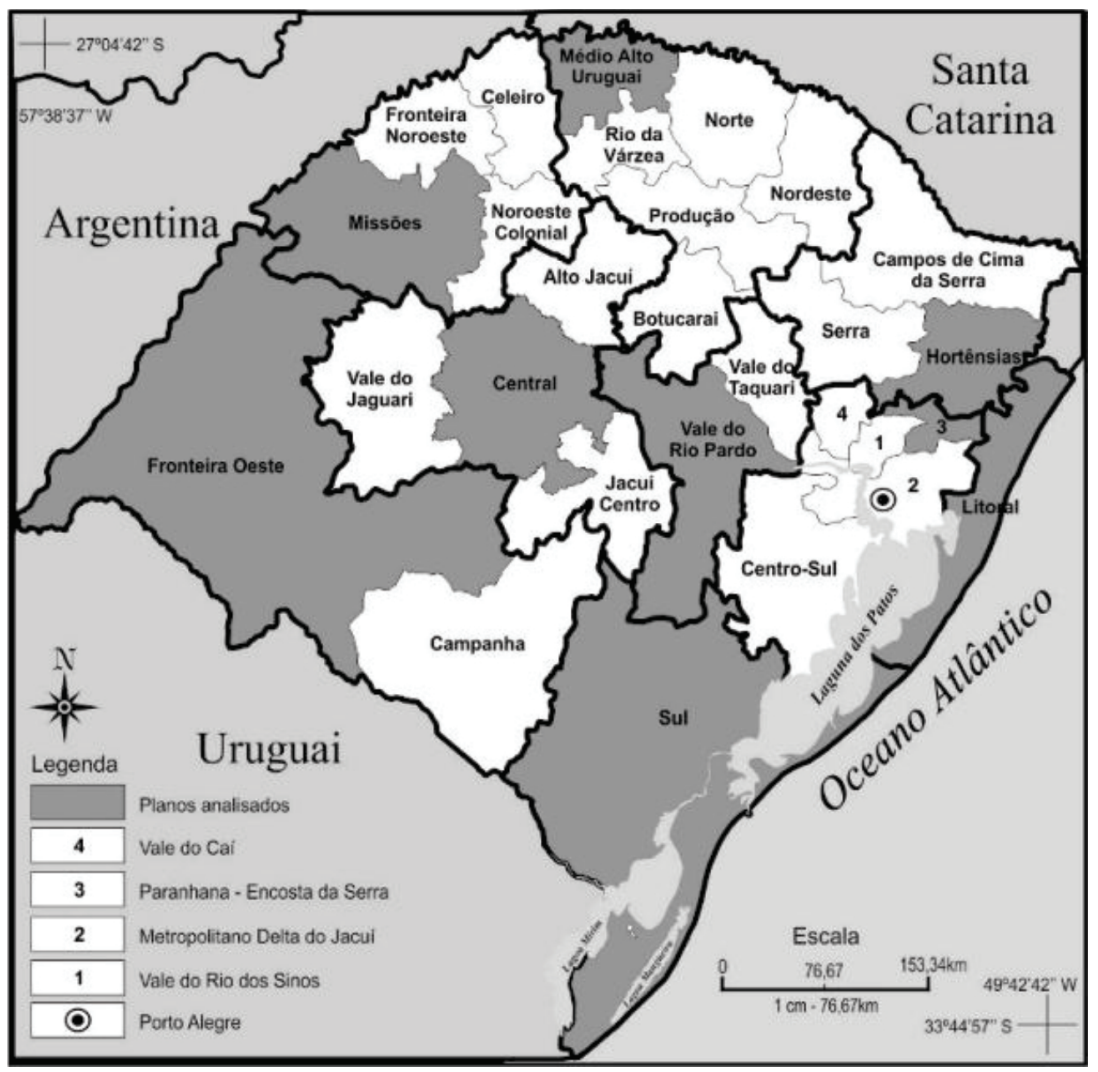

Fonte: Rio Grande do Sul (2006), adaptado pelo autor.

A obtenção das demandas eleitas da Consulta Popular $2010^{7}$ ocorreu diretamente no sítio $^{8}$ institucional da própria consulta, o qual é gerido pela Secretaria de Planejamento, Gestão e Participação cidadã do Governo do Estado do Rio Grande do Sul.

O cruzamento das demandas eleitas pela Consulta Popular e os projetos elencados pelos Planejamentos Regionais ocorreu da seguinte forma: primeiro se confeccionou uma tabela base para o cruzamento, sendo que no eixo ' $x$ ' foram descritos os projetos oriundos dos planos, e no ' $y$ ' as demandas eleitas. Por conta do grande número de projetos elencados pelos planejamentos - em alguns planos mais de 50 - nas tabelas foi considerada a totalidade das demandas eleitas - que somam aproximadamente entre 5 e 10 por COREDE. Segundo, foi buscado

As demandas eleitas de 2011 ainda não foram disponibilizadas.

8 Disponível em < http://www.consultapopular.rs.gov.br/>. 
entre os vários projetos descritos pelos planos, algum que guardava relação direta - marcado com a cor cinza escuro -, ou seja, descrição igual ou próxima com a demanda eleita na Consulta, indireta - marcado com cinza claro - que possui relação, porém não propriamente o descrito na demanda, ou em branco, sendo que não há relação. A tabela 1 representa como foi realizado o cruzamento.

Tabela 1. Exemplo do cruzamento realizado entre demandas eleitas pela Consulta Popular 2010 e projetos elencados pelos planejamentos regionais 2009/2010.

\begin{tabular}{l|l|l|l}
\hline $\begin{array}{l}\text { Demandas eleitas / } \\
\text { Projetos propostos }\end{array}$ & Projeto 1 & Projeto 2 & Projeto 3 \\
\hline Demanda 1 & & & \\
\hline Demanda 2 & & & \\
\hline Demanda 3 & & & \\
\hline
\end{tabular}

\section{RESULTADOS E DISCUSSÕES}

A Consulta Popular 2010 elegeu quatro estratégias tidas como prioritárias para cada COREDE do Rio Grande do Sul. Destas quatro é (são) detalhado(s) qual(is) projeto(s) deverá(ão) ser executado(s), onde - se a nível regional ou em um município específico - e o valor destinado.

Devido ao parco detalhamento de alguns COREDEs junto as suas estratégias, a análise foi de certo modo, prejudicada, pois não há como ter clareza sobre os investimentos eleitos na Consulta, assim dificultando o cruzamento com os projetos descritos nos planejamentos. Os Conselhos que detalharam suas propostas na Consulta foram conferidos em sua totalidade.

Contudo, os resultados apresentam um satisfatório retrato da perspectiva de desenvolvimento, planejamento e orçamento participativo do Estado, como será visto a seguir. Primeiramente serão pontuados aspectos por COREDE, posteriormente serão abordados resultados gerais da pesquisa.

No COREDE Paranhana - entre as quatro estratégias norteadoras eleitas, há 13 projetos descritos, destes nove tem relação direta com projetos oriundos do planejamento regional, um tem relação indireta e três não possuem proximidade. Percebe-se que há uma concordância entre o descrito no planejamento e o eleito na Consulta, especialmente com destaque aos projetos do segmento da saúde, tecnologia e segurança, sobre os quais os detalhamentos têm forte intersecção.

No Vale do Rio Pardo - foram detalhados oito demandas na Consulta Popular, nas quais, três tem relação direta com projetos do plano regional, outros 
três com perspectivas indiretas e dois sem qualquer proximidade. Considerando os projetos com afinidade, a questão do esgotamento sanitário apresenta-se como uma carência exponencial da região, pois, esta descrita de forma densa no planejamento como uma necessidade, e contempla uma demanda na Consulta Popular.

No COREDE Hortênsias - há o primeiro caso de parco detalhamento nos projetos eleitos na Consulta, sendo que apenas as quatro estratégias base são descritas, sem grande aprofundamento. Duas demandas tem proximidade direta com projetos apontados nos planejamentos, às outras duas indiretas. Entretanto, apesar de considerar que o planejamento regional foi fonte para elencar as demandas da Consulta, por estar sem grandes especificações pode-se questionar se as demandas eleitas realmente tem relação com os projetos descritos no plano.

Dentre os Conselhos analisados, o COREDE Litoral Norte - é o que menos apresenta relação entre as demandas eleitas e o estudo realizado pelo COREDE em 2009/2010, visto que dentre os nove projetos detalhados pela Consulta, cinco não possuem proximidade alguma com o plano - dos outros quatro, dois tem relação direta e dois indireta.

O COREDE Sul - entre os analisados, foi o que mais detalhou suas quatro demandas eleitas, sendo que são descritos vinte e um projetos na Consulta Popular 2010, dos quais nove tem relação direta com os projetos do planejamento, três indireta e outras nove sem proximidade. As necessidades básicas da saúde, além da qualificação da oferta turística, apresentam-se como elementos de maior destaque na relação Consulta Popular e planejamento regional.

No COREDE Fronteira Oeste - são seis demandas descritas na Consulta, sobre as quais duas tem relação direta e quatro não possui nenhuma afinidade com os projetos elencados no planejamento. Percebe-se a baixa relação entre Consulta e planejamento regional, de modo que entre as demandas eleitas não estão em acordo com as necessidades regionais captadas pelo estudo realizado pelo COREDE.

Sobre as quatro demandas eleitas no COREDE Missões - apenas cinco projetos detalhados, dos quais três tem proximidade direta com os elencados pelo planejamento e os outros dois não possuem relação. Saúde e a melhoria nos acessos rurais estão entre as demandas principais da região.

O COREDE Central - também detalhou em apenas cinco projetos, sobre os quais quatro guardam proximidade direta com o plano e uma indireta. $\mathrm{Na}$ região, o aparelhamento de hospitais e a reforma de tais espaços são preocupações latentes tanto entre a população que elegeu esta demanda como dos agentes planejadores. 
Por fim, o COREDE Médio Alto Uruguai - apenas menciona as próprias quatro estratégias eleitas, das quais três tem relação direta com os resultados dos planos e uma sem proximidade. O planejamento aparentemente foi considerado, contudo, devido ao aspecto pontual em que estão colocadas as demandas eleitas, não se pode afirmar que tais investimentos tem relação com o detectado no planejamento.

Com esta breve descrição do cruzamento entre demandas eleitas pela Consulta Popular e projetos mencionados nos planejamentos dos COREDEs 2009/2010 como necessários para o desenvolvimento das regiões, algumas considerações podem ser tecidas em âmbito geral, sobre como está ocorrendo o planejamento do Estado e o processo de orçamento participativo.

Considerando a perspectiva de planejamento regional abordada por Boisier (2000), em que o resultado apresenta a gama de ações tidas como necessárias para estimular processos de crescimento, e eventualmente, de desenvolvimento, e as afirmações de Bugs (2011) sobre a Consulta Popular, na qual o Estado ouve a sociedade civil sobre projetos necessários para o desenvolvimento, pode-se realizar uma crítica aos dois procedimentos análisados neste trabalho.

Primeiro, apesar das necessidades básicas da população ser de suma importancia para realizar projetos de desenvolvimento, estes, antes de tudo, são básicos. Pensar desenvolvimento a partir destes requer uma forte especialização nestes ramos que vão muito além de suprir o básico junto à população.

Segundo, perceber o planejamento e a Consulta Popular como mecanismos para atingir determinado desenvolvimento, portanto, remete-se em ir além de eleger necessidades básicas como pontos fundamentais, como ocorreu entre as demandas eleitas da Consulta Popular, onde grande parte do espaço é coberto por estes elementos que não deveriam ser postos em votação, pois são atributos básicos e responsabilidade do Estado em cobrir tais ausências, e não remeter a projetos visando o desenvolvimento o encargo de destinar recursos, como no caso do aparelhamento dos órgãos de segurança pública, presente em todos os COREDEs.

Portanto um redirecionamento é necessário junto à finalidade da Consulta Popular, visto que contemplar aspectos básicos para a população, apesar de serem de primordial importância, não remetem essencialmente a projetos de desenvolvimento. Estas demandas provavelmente continuarão sendo contempladas entre as estratégias eleitas caso não haja uma redefinição da função da Consulta Popular.

O Estado do Rio Grande do Sul deve, por intermédio de outras formas, buscar sanar carências nas áreas de saúde e segurança pública, resguardando 
a Consulta e aos planejamentos regionais 'apenas' a discussão direta sobre o desenvolvimento, e não para atender necessidades básicas de equipamentos e estrutura.

Da mesma forma, os COREDEs, ao elencar as demandas a serem votadas, precisam realizar com maior acuidade uma revisão do exposto nos planejamentos regionais realizados por eles mesmos, pois, com exceções, projetos são postos a votação sem haver uma real problematização, resultando em demandas eleitas sem proximidade com os projetos dos planejamentos.

\section{CONCLUSÃO}

Numa retomada da perspectiva territorial quando se pensa o desenvolvimento, pensar o planejamento em qualquer escala como uma forma de perceber as carências e potencialidades de tal território para se auferir o desenvolvimento torna-se uma necessidade, um meio. Da mesma forma, os mecanismos de Orçamento Participativo podem auxiliar, tanto para a sociedade civil participar do processo de definição de investimentos, quanto para a materialização dos planos.

O presente artigo pretendeu responder se os planejamentos regionais, realizados pelos COREDEs nos anos de 2009/2010, foram considerados nas demandas eleitas da Consulta Popular 2010, a partir de uma revisão bibliográfica e da análise dos planos das demandas eleitas pela Consulta.

Percebeu-se que entre os nove COREDEs analisados houve relações heterogêneas entre planejamentos e Consulta popular, sendo que alguns COREDEs consideram com maior ênfase o descrito nos planos para elencar as demandas a serem votadas.

Dentre as demandas, destacaram-se as de necessidade básica da população, como a instrumentalização dos órgãos de segurança pública, que, apesar de ser de suma importância, expõem a dificuldade de utilizar os mecanismos para obter projetos que resultem desenvolvimento, visto que, com o não atendimento por parte do Estado nas questões básicas, o planejamento sendo realizado de forma participativa, e a Consulta Popular uma consulta direta a população, estas problemáticas básicas apareceram nos resultados, desviando-se do objetivo.

Deveria, portanto, o Estado do Rio Grande do Sul, através de outras formas, atender a população com serviços básicos satisfatoriamente, não renegando a mecanismos que visam promover o desenvolvimento realizar tais funções. $\mathrm{Na}$ mesma medida, os COREDEs têm de desviar atenção para os projetos elencados 
pelos planejamentos quando forem mencioná-los na Consulta Popular, pois estes projetos presumem um estudo e discussão com a sociedade civil organizada como necessários e promotores de desenvolvimento regional.

\section{REFERÊNCIAS}

BENKO, Georges. A Ciência Regional. Oeiras: Celta Editora, 1999.

BOISIER, Sergio. El Desarrollo territorial a partir de la construcion de capital sinergético. Curso Internacional Ciudad Futura II: Rosario, 2000.

BUGS, João Carlos. Abordagem estratégica dos processos de desenvolvimento socioeconômico regional: o caso do COREDE VRP. Santa Cruz do Sul: Dissertação de Mestrado/UNISC, 2011.

CAMPOS, Heleniza Ávila; CHRISTOFF, Mariza Terezinha da Motta (orgs.). Plano estratégico de desenvolvimento do Vale do Rio Pardo (RS). Santa Cruz do Sul: EDUNISC, 2010.

CONSELHO REGIONAL DE DESENVOLVIMENTO DA FRONTEIRA OESTE. Planejamento Estratégico (2010-2020). São Borja: Conselho Regional de Desenvolvimento da Fronteira Oeste, 2010.

CONSELHO REGIONAL DE DESENVOLVIMENTO DA REGIÃO CENTRAL. Caminhos 2030: relatório planejamento regional. Santa Maria: COREDE Central, 2010.

CONSELHO REGIONAL DE DESENVOLVIMENTO DA REGIÃO DAS HORTÊNSIAS. Plano estratégico de desenvolvimento da região do Conselho Regional de Desenvolvimento Hortênsias. Canela: Conselho Regional de Desenvolvimento da Região das Hortênsias, 2010.

CONSELHO REGIONAL DE DESENVOLVIMENTO DA REGIÃO SUL. Plano estratégico de Desenvolvimento da Região Sul do RS. Pelotas: Editora Cópias Santa Cruz Ltda, 2010.

CONSELHO REGIONAL DE DESENVOLVIMENTO DAS MISSÕES. Planejamento Estratégico Regional. Santo Ângelo: Conselho Regional de Desenvolvimento das Missões, 2010. 
CONSELHO REGIONAL DE DESENVOLVIMENTO DO LITORAL NORTE. Planejamento Estratégico Litoral Norte. Osório: CentroLegis, 2010 .

DALLABRIDA, Valdir Roque. Planejamento regional: algumas observações teóricas e análise da prática. REDES, Santa Cruz do Sul, v. 9, n. 1, p. 37 - 61, jan./abr. 2004.

FÓRUM DOS CONSELHOS REGIONAIS DE DESENVOLVIMENTO DO RIO GRANDE DO SUL. PRÓ-RS: propostas estratégicas para o desenvolvimento regional do Estado do Rio Grande do Sul. Passo Fundo: Passografic, 2010.

GIRARDI et al. Palno estratégico de desenvolvimento regional. Frederico Westphalen: Grafimax, 2010.

HARVEY, David. Condição pós-moderna: uma pesquisa sobre as Origens da Mudança Cultural. São Paulo: Edições Loyola, 1992.

HOLANDA, Nilson. Planejamento e Projetos. Fortaleza: UFC, 1983.

LENCIONI, Sandra. Região e Geografia - a noção de região no pensamento geográfico. IN: CARLOS, Ana Fani. Novos Caminhos da Geografia. São Paulo: Contexto, 2001.

MENGDEN, Paulo Roberto de Aguiar von (org.). Plano estratégico de desenvolvimento regional. Taquara: COREDEPES, 2010.

PECQUEUR, Bernard. A guinada territorial da economia global. Política \& Sociedade - Revista de Sociologia Política, PPSP UFSC, 2009.

PIRES, Valdemir. Orçamento Participativo: O que é, para que serve, como se faz. Barueri: Manole, 2001.

RIO GRANDE DO SUL, Secretaria da Coordenação e Planejamento. Departamento de Estudos Econômicos e Sociais e Planejamento Estratégico. Rumos 2015: estudo sobre desenvolvimento regional e logística de transportes no Rio Grande do Sul. Porto Alegre: SCP, 2006.

SANTOS, Milton. A natureza do espaço: Técnica e tempo. Razão e Emoção. São Paulo: Hucitec, 1996.

O papel ativo da Geografia - um manifesto. In. XII Encontro Nacional de Geógrafos, Florianópolis, SC. Anais... Florianópolis: UFSC, 2000. 
SIEDENBERG, Dieter (org.). Fundamentos e técnicas de planejamento estratégico local/regional. Santa Cruz do Sul: EDUNISC, 2010.

Orientações para o processo de Planejamento Estratégico Regional dos COREDES-RS. Ijuí: Unijuí, 2009.

Sítio - Consulta Popular RS - http://www.consultapopular.rs.gov.br/ - acesso em 21/10/2011.

TRIVIÑOS, Augusto Nibaldo Silva. Bases teórico-metodológicas da pesquisa qualitativa em ciências sociais. Porto Alegre: Ritter do Reis, 2001. 